\title{
Die agtste deel van die Woordeboek van die Afrikaanse Taal
}

\author{
Edith H. Raidt, Universiteit van die Witwatersrand, \\ Johannesburg, Suid-Afrika
}

\begin{abstract}
Volume VIIl of the Woordeboek van die Afrikaanse Taal ("Dictionary of the Afrikaans Language"). Since its inception in 1926 as a government funded project, the Woordeboek van die Afrikanse Taal has undergone repeated editorial changes which caused extensive delays in the publication of volumes I-VIII (1951-1991) and, quite understandably, elicited serious criticism. With the publication of Volume VIII the letter $K$ is at long last completed. It has taken three decades to compile the words starting with $\mathrm{K}$. Such a delay is totally unacceptable and one can only hope that the future volumes will appear in reasonably quick succession. Volume VIII seems to be a volume in transition concerning editorial policy. Great progress has been made in avoiding the much criticised encyclopedic approach of preceding volumes, the articles are better structured, semantic definitions are on the whole succinct, but the quotations are still too numerous and without any clear sequence. The main points of criticism expressed in this article concern (1) the random choice and ordering of quotations; (2) the lack of consistent etymological references, (3) the lack of historical principles.

However, Volume VIII contains many signs of promising developments which seem to indicate that the future volumes will be the fruit of clearly defined editorial policies, resulting in speedy, yet thorough publications.
\end{abstract}

Keywords: AFRIKAANS, ANGLICISM, CITATION, COMPOSITUM, DEFINITION, DERIVATION, DICTIONARY, EDITORIAL POLICY, ENGLISH, ETYMOLOGY, HISTORICAL PRINCIPLES, IDIOM, (VERBAL) ILLUSTRATION, LEMMA, LEXICOGRAPHY, LOANWORD, NEOLOGISM, REGIOLECT, SOCIOLECT, STANDARD LANGUAGE, TERMINOLOGY, VARIANT

Opsomming: Vanaf sy begin in 1926 het die Woordeboek van die Afrikaanse Taal baie ingrypende redaksionele wysigings ondergaan. Dit het veroorsaak dat die publikasie van dele 1 tot VIll (1951-1991) met onaanvaarbaar lang vertragings gepaard gegaan het. Met WAT VIIl is die letter K - na drie dekades - uiteindelik klaar. Hierdie deel is klaarblyklik die produk van 'n oorgangsfase in die redaksionele beleid. Dit is veel strakker in die aanbod, die artikels is beter gestruktureer, die betekenisdefinisies is op min uitsonderings na nie meer ensiklopedies van aard nie. Daar is egter nog steeds onnodig baie en sleg geordende voorbeeldmateriaal wat nie op historiese beginsels gebaseer is nie hoewel daar indirek waardevolle historiese inligting verskaf word. Die hoofkritiek wat in hierdie artikel geopper word, het betrekking op (1) die lukraak keuse van aanhalings; (2) die wegskram van etimologieë; (3) die afwesigheid van historiese beginsels. 
WAT VIII toon egter in baie opsigte 'n belowende vooruitgang. Dit laat 'n mens uitsien na 'n beter omlynde redaksionele beleid wat hopelik sal lei tot 'n deeglike en spoedige voortsetting van die Woordeboek van die Afrikanse Taal.

Sleutelwoorde: AFLEIDING, AFRIKAANS, ANGLISISME, DEFINISIE, ENGELS, ETIMO LOGIEë, HISTORIESE BEGINSELS, IDIOME, LEENWOORDE, LEKSIKOGRAFIE, LEMMA, NEOLOGISMES, POËME, REDAKSIONELE BELEID, REGIOLEK, SAMESTELLING, SITAAT, SOSIOLEK, STANDAARDTAAL, TEGNIESE TERME, TERMINOLOGIE, VARIANT, WOORDEBOEK

\section{Inleiding}

As "n mens van 'n "leksikografiese generasie" kan praat dan is dit van toepassing op die optekening van die letter $\mathrm{K}$ in die Woordeboek van die Afrikaanse Taal (voortaan WAT), want dit het die leksikograwe van die Woordeboek-redaksie dertig jaar geneem om die letter $K$ te behandel en af te rond. $K$ is wel op een na die langste letter in ' $n$ Afrikaanse woordeboek, nogtans bly dit 'n onaanvaarbare slakkepas; mens kan net hoop dat so 'n vertraging in die toekoms nie meer gebeur nie. Met die verskyning van die Agtste Deel van die WAT (KOSKYWIEHOUER), wat 584 bladsye beslaan en van 'n uitgebreide inleiding (12 paginas) voorsien is, het die taalgebruiker egter ' $n$ belangrike toevoeging tot sy broodnodige naslaanwerke gekry. $\mathrm{Al}$ is ons nou nog nie eens halfpad deur die alfabet nie, is 'n mens tog dankbaar vir hierdie vooruitgang wat bowendien selfs belowend lyk.

Die WAT het ' $n$ uiters trae begin gehad. Reeds in 1926 is die projek onder leiding van prof. J.J. Smith van stapel gestuur met die verondersteling dat dit teen 1936 voltooi sou wees. Die bedoeling was om 'n deskriptiewe woordeboek van die standaardtaal op te stel, 'n soort Afrikaanse Van Dale (Gouws en Ponelis 1992: 21-23). Maar van die begin af het sake anders verloop want prof. J.J. Smith se beleid was veel meer omvattend. Soos uit die materiaalversameling van die vroeë jare blyk, het hy 'n groot aantal nie-standaardvorme opgeteken. Die gebrek aan 'n duidellke en haalbare redaksionele beleid het die publikasie met dekades vertraag. Volgens Gouws en Ponelis (1922: 22) het dit gelei

... to a divergence between this dictionary and the main stream research in Afrikaans linguistics. This divergence resulted in the linguistic isolation of the WAT, but in addition it diminished the potential influence on the development of Afrikaans of the most expensive and comprehensive lexicographical and linguistic project within that language community.

Ten tye van J.J. Smith se aftrede was daar nog geen persklaar manuskrip gereed nie. Nadat P.C. Schoonees die hoofredakteur geword het, verskyn in 1950 deel I (A-C), vyf jaar later deel II (D-F), deel III (G) volg in 1957 en deel IV 
$(H-I)$ in 1961. Van toe af sloer die saak egter weer. Eers sewe jaar later verskyn deel $\mathrm{V}(\mathrm{J}-\mathrm{KJ})$ en word daar met die letter $\mathrm{K}$ begin wat na ' $\mathrm{n}$ pouse van 8 jaar in 1976 uiteindelik voortgesit word in deel VI (KLA-KOL). Na nog 'n pouse van agt jaar verskyn deel VII wat die letter $K$ vanaf $K O M$ tot by $K O R$ - behandel. Maar toe is $K$ nog steeds ver van klaar. Die hoofredakteurs vir die dele V en VI was F.J. Snijman, vir VII en VIII D.C. Hauptfleisch. Onder die hoofredakteurskap van dr. Snijman het die WAT al hoe meer ensiklopedies van aard geword wat nie tot voordeel van dle Woordeboek was nie. Dit het dan ook duidelik in die kwaai maar regverdige kritiek wat veral deel VI uitgelok het, tot uiting gekom (vgl. Combrink 1979 en Odendal 1979).

Dit is tog vreemd dat 'n ander belangrike en rigtinggewende naslaanwerk in dieselfde tydperk ook besonder lank gesloer het, $\mathrm{nl}$. die sewende uitgawe van die Afrikaanse Woordelys en Spelreëls (1991, voortaan AWS); wat 'n volle 27 jaar na die vorige uitgawe gepubliseer is. Wat het in die afgelope drie dekades, wat andersins gekenmerk was deur vooruitgang en vinnige ontwikkeling op amper alle lewensterreine, gebeur om dergelike vertragings toe te laat? Gebrek aan taalkundige leiding en inisiatief? Verwaarlosing van die leksikografie as 'n taalkundige dissipline? Of diepgaande herbesinning en heroriëntering t.o.v. die beskrywing van die Afrikaanse leksikon? Die jongste AWS getuig beslis van 'n nuwe benadering, veral teenoor leenwoorde en neologismes en is in die opsig die WAT vooruit.

\section{Tradisie én vooruitgang}

Hoewel deel VIII nog duidelik in die tot dusver gebruiklike tradisie van die WAT I-VII staan, is daar tog opvallende verbeterings. Die ensiklopediese aanbod is nog nie heeltemal uitgeskakel nie maar dis aansienlik besnoei. Daar is tekens van 'n strakker aanbod van die leksikale items; die artikels is beter gestruktureer; die oordadige aanbod van aanhalings word oor die algemeen besnoei hoewel dit tog plek-plek nog kop uitsteek. Die "Toeligting by die gebruik van die Woordeboek" (pp. viii-xix) getuig van 'n nuwe benadering, en veral van ' $n$ beter verantwoording en sistematisering a.g.v. 'n strakker redaksionele beleid. In teenstelling met vorige dele word daar pertinent op terminologieverklaring, rangskikking en vorm van artikels, samestellings en afleidings, verwysingsmetodes by wisselvorme, variante, sinonieme en antonieme en ander aspekte ingegaan wat getuig van die redaksie se meer sistematiese benadering en meer doeltreffende beskrywing van leksikale items en die verwerking van die data. Oor die algemeen is daar 'n groot vooruitgang in die betekenisdefinisies van woorde. In teenstelling met die omslagtigheid van bv. WAT VI, word betekenisse nou meestal in kort sinne met tersaaklike inligting verskaf. 'n Mens verwelkom die goed verantwoorde betekenisonderskeiding, betekenistoepassing en betekenisindeling soos vermeld in die Toeligting pp. viii, xi, en die aandag wat aan homonieme gegee word. Lg. word omskryf as 
Leksikale item met dieselfde vorm (spelling) as 'n ander, maar waarvan die betekenis sodanig verskil dat die leksikale items tans as onverwant aan mekaar beskou word, ongeag of hulle 'n gemeenskaplike of verskillende herkoms het (p. viii).

Hoewel die term polisemie nie in die "Terminologieverklaring" opgeneem is nie, word die verskil tussen homonimie en polisemie tog gehandhaaf en op grond van sinchroniese oorwegings gemaak. Soos Gouws (1989: 126) opmerk, verg "die korrekte leksikografiese hantering van polisemiese gevalle ... deeglike taalkundige insig". Hier toon die leksikograwe van WAT VIII goeie oordeel en knap hantering van homonieme en poliseme.

Nie alle artikels. volg dieselfde patroon nie. Sommige is hegter saamgestel as ander, soms is daar nog steeds onnodige aanhalings; soms is die verklarings tog nog aan die ensiklopediese kant (bv. by kriterium, kropmelk, kroton e.a.); en wat die keuse van opname en behandeling in die vorm van artikels betref, wil dit voorkom of daar nog nie 'n duidelik omlynde strategie bestaan nie. Gevolglik kry 'n mens die indruk dat hierdie deel 'n soort oorgangsfase daarstel en dat die redaksie besig is om 'n nuwe beleid t.o.v. die volgende dele van die Woordeboek te ontwikkel: Dit sou beslis 'n wenslike ontwikkeling wees wat deur die woordeboek-gebruiker verwelkom sal word.

\section{Bronne}

Die leksikale items van deel VIII is op ' $n$ indrukwekkende en redelike verteenwoordigende databasis uit meer as 3000 bronne gebaseer. Eintlik sou 'n mens meer bronne oor regionale Afrikaans daarby wou gehad het, bv. die studies van Tony Links, So praat ons Namakwalanders (1989), Van der Waal-Braaksma en Ferreira, Die Noordweste (1986), Hans du Plessis, Suidwesafrikaans (1985), om slegs enkeles te noem. Maar hierdie beperking tot "Standaardafrikaans" kan dalk as 'n terugkeer tot die oorspronklike opset van die. WAT beskou word, want die WAT was aanvanklik bedoel om ' $n$ standaard-deskriptiewe woordeboek te wees.

Hier lê vir my 'n byna tragiese mistasting waardeur gulde geleenthede verpas is. In die dertiger- en veertigerjare het daar juis ' $n$ enorme behoefte bestaan aan 'n standaard-woordeboek 'wat sou kon bygedra het tot die standaardisering van Afrikaans. Hierdie standaardisering het hom voltrek sonder die hulp en die rigtinggewende leiding van die WAT. Na die Soweto-opstande in 1976 en dan veral in die tagtiger- en vroeee neëntigerjare het die verset teen 'n plek-plek eksklusiewe en onsensitiewe standaardtaal egter tot uiting gekom in die aandrang op 'n "alternatiewe Afrikaans" wat ook die regiolekte en sosiolekte van die hele Afrikaanssprekende bevolking sou verteenwoordig. Ook hierdie ontwikkeling voltrek hom blykbaar sonder die hulp van die WAT, en weer 
eens wil dit voorkom of die Woordeboek uit die pas raak met die ontwikkelings in die spraakgemeenskap.

\section{Neologismes, leenwoorde en leenvertalings}

Heelwat bronne dateer uit die tagtigerjare en weerspieël dus iets van die meer resente taalgebruik soos uit onderstaande voorbeelde blyk.

Nuwe woorde van die afgelope drie dekades verraai dikwels Engelse invloed, bv. kovert (Eng. covert), kothuis (volksetimologies vir Eng. cottage), kwad (Eng. quad). Dit geld ook vir leenvertalings soos kousbroekie en broekieskouse (Eng. pantihose), kweekhuistoestand, kweekhuiseffek (Eng. greenhouse effect), kropskêr (Eng. crop shears); woorde soos kruisneef, kruisniggie is leenvertalings uit swart tale.

Sommige woorde het gekom en gegaan soms sonder dat hulle vermelding kry: krimpelien (sintetiese materiaal uit die sewentigerjare) is byvoorbeeld nie opgeneem nie, terwyl krinolien ("stywe weefstof van perdehaar of katoen") uit die ou dae wel vermeld en selfs in drie artikels, mét aanhalings bespreek word. Die meeste neologismes illustreer Afrikaans se byna eindelose vermoë om samestellings en afleidings te maak, bv. kykaand, kykbaar wat die nuwe tydperk van TV weerspieël, krotbuurte, kreukelvry, krimptraag, krimpbaar, kruisbaar, krummelbaar, kuierkoop en die nogal onsuksesvolle kroostrooster, almal uit die jare sestig, sewentig en daarna.

Dit is opvallend dat die AWS dikwels meer resente woordvormings en uitspraakvariante bevat en daardeur meer progressief voorkom as die WAT VIII. Die AWS het bv. (uiteindelik!) die totaal verouderde kosthuis weggelaat, terwyl dit in WAT VIII nog steeds as wisselvorm van koshuis verskyn. Die AWS het die (Anglisistiese) variante kousjer naas kosjer, kreip naas crêpe, in heerlike nuutskepping soos kyk-in-die-pot (Eng. potluck) en 'n resente "vakterm" KwaZulu wat in die WAT VIII ontbreek. Die AWS openbaar 'n innoverende rigting wat nie in dieselfde mate in die WAT voorkom nie. Die weglating in WAT VIII van veel gebruikte Anglisismes wat bv. in Van der Merwe en Ponelis, Die korrekte woord (1991) wel opgeneem is, skep die indruk van 'n normatiewe optrede waardeur dergelike leenwoorde nog nie in die "standaardwoordeboek" aanvaarbaar is nie.

\section{Lemmas}

Uit die Toeligting blyk dat die redaksie hulle behoorlik rekenskap gegee het van wat hulle as ' $n$ lemma beskou. Hulle definisie is handig en insiggewend:

lemma. Elk van die leksikale items wat verklaard in die Woordeboek opgeneem, in vet druk gegee en alfabeties gerangskik word. Onverklaar- 
de samestellings en afleidings van sò 'n lemma word binne die stelsel van die Woordeboek nie as lemmas beskou nie maar word afsonderlik gealfabetiseer en as laaste inskrywing onder die betrokke lemma saamgegroepeer. (p. ix)

Verreweg die meeste van die nagenoeg 11000 leksikale items word as aparte lemmas behandel, meer as 7000 van hulle met verklarings in aparte artikels, en ongeveer 4000 daarsonder. Dit het sy voor- en nadele. Aan die een kant word die naslaanwerk daardeur vergemaklik, aan die ander kant kan dit tot onnodige, met aanhalings geillustreerde lemmas lei, wat kosbare ruimte in beslag neem. 'n Mens verwelkom die aparte inskrywings van iteratiewe. Op enkele uitsonderings na (bv. kreupel-kreupel, kroes-kroes, krom-krom) word hulle as aparte lemmas behandel en met aanhalings geillustreer, maar dit sou wenslik wees om hier 'n vaste beleid te volg.

By wisselvorme word soms onnodige artikels gemaak; bv. word die variante kruisement, kruisemint, kruisemunt, kruistemint, kruistemunt met aanhalings in 5 lemmas vermeld, krokkedel, krokodel en krokodil in 3 lemmas, en kwaaivriende, kwaaivrinde en kwaaivrinne, ook in 3 lemmas, en almal mét aanhalings. Hier skemer die ou redaksionele onduidelikheid deur, en nog steeds die gebrek aan 'n vaste redaksionele beleid t.o.v. die opname al dan nie van regionale variante.

Seldsame of idiosinkratiese woordvormimgs soos koster-skoolmeester, of Adam Tas se spottend bedoelde krankebedroewer en die uiters ongewone kultuureners is mi. nie 'n aparte inskrywing werd nie. Hier behoort die redaksie meer selektief te wees. As ' $n$ woord slegs een keer of by een bepaalde skrywer voorkom, is dit nie noodwendig deel van die Afrikaanse leksikon nie. Dan sou 'n mens beslis veel meer gewestelike variante en lekker sêgoed, bv. uit Namakwalandse Afrikaans, Griekwa-Afrikaans ens. moet opneem. In dié verband waardeer 'n mens 'n regionale woord soos kos-my-niks (volksetimologies uit Eng. cosmetics) wat soortgelyk is aan oliekolonie (volksetimologies uit Frans eau de Cologne).

Verskeje Khoi-woorde word in aparte artikels behandel, soms met etimologiese verwysings soos in kousa en kousang < Hott. \#kou, "smeer" en sa, "boegoe"), kouroe <!kouroe = "klipgat", soms is daar slegs die opmerking <Hott., bv. by koubee. In teenstelling met ander artikels val dit op dat by Khoi-woorde bitter min aanhalings verskaf word, wel word daar melding gemaak van die plek waar die woorde opgeteken is.

Dit is vir my nie duidelik of en wanneer 'n leksikale item 'n aparte inskrywing "verdien" nie. Hoekom word samestellings soos kroonslagaaromleiding, kroonslagaarsiekte, kroonslagaartrombose, kroonslagaarverstopping in aparte artikels behandel terwyl kroonslagaaraandoening, -behandeling, -bloedstroom, -operasie e.a. slegs as onverklaarde samestellings aangedui word? Waarom word 'n hoogs gespesialiseerde mediese vakterm soos Krim-Kongokoors mét verskeie aanhalings opgeneem en in 'n ärtikel beskryf met daarby 
nog twee verdere samestellings as onverklaarde samestellings? Ons kry lemmas vir krom-Hollands, krom-Nederlands en krom-Portugees terwyl kromAfrikaans en krom-Engels nie eens vermeld word nie. Hier behoort 'n strakker beleid ontwikkél te word om dergelike ongerymdhede uit te skakel.

Een van die swakste aspekte van die artikel-inskrywings is die gebruik en ordening van voorbeeldmateriaal. Dit wil voorkom of die voorbeeldsinne met bronneverwysing en datum - lukraak gerangskik is. Ek kan nóg 'n chronologiese nóg 'n semantiese ordening ontdek. Die aantal voorbeeldsinne is in verdere probleem soos later bespreek sal word.

\section{Samestellings en afleidings}

'n Interessante aspek wat 'n mens by die deurlees van deel VIll opval, is die aard en die groot hoeveelheid samestellings en afleidings wat vermeld word. Ek volstaan met 'n paar voorbeelde. Daar is 358 samestellings met kultuur-, almal as aparte lemmas, afgesien van nog verdere lektiese items met dieselfde stam. Daar is letterlik honderde samestellings en afleidings met die stamme krag-, kruis- en kuns-. Die selfstandige naamwoord kryg mag "tans verouderend" wees, maar die meeste samestellings en afleidings is beslis nog baie gebruiklik, soos blyk uit die 153 lemmas met die stam kryg-, bv. krygsgevangene, krygsmakker, krygswet, krygslustig. Natuurlik figureer ook die tegnosamestellings en -afleidings taamlik sterk met talle lemmas i.v.m. kosmo-, krio-, kwadraat-, kwantum- ens.

Soms sit in die samestellings interessante brokkies taalgeskiedenis. Die kompositum kreefkerrie kom bv. reeds in Peter Kolb se Beschreibung voor, "Zy ... smaken best, als men kreeft kerria, dat is een zoort van goede, gezonde en lekkere spys, daar uit gemaakt heeft". (Deel I, 1727: 239a) WAT Vlll vermeld ook die bekende uitdrukking in ouer Afrikaans "Ek laat nie kreefkerrie van my maak nie" (Scholtz 1965: 171). Uit hierdie voorbeeld blyk dat die WAT soms wel aanhalings uit ou bronne verskaf al is dit op 'n lukraak manier.

\section{Vaktale}

Dit is nie duidelik watter beleid by die vermelding van vakterme uit bepaalde vakrigtings en sosiolekte toegepas word nie. Heelwat mediese en veral tegnologiese terme, landbou- en wetenskapsterme is in deel VIIl opgeneem, en sommige is vir die leek baie gespesialiseerd. Maar 'n vaste beleid ontbreek.

As voorbeeld van 'n goed gedokumenteerde vaktaal of sosiolek kan hier verwys word na die Rooms-Katolieke terme wat amper volledig verteenwoordig is in deel VIII, bv. kromstaf, kruieseëning, kruin, kruinskering, kurie (curia), kwatertemperdag (verouderd), kruisaanbidding, kruisverering, kruisverheffing, kruisweg(stasie), Kyrie, kyriaal. Slegs enkele woorde en 
vaste uitdrukkings soos Kosbare Bloed (van Christus), kruisstaf in die betekenis van kromstaf, "biskoplike herderstaf" (Eng. crozier) ontbreek. Dit wil voor. kom of hier hoofsaaklik vanaf die ongepubliseerde $\mathrm{PhD}$ verhandeling van D.J. Gomes (1962) gewerk is en nie so seer aan die hand van die meer gesaghebbende tweetalige Church Dictionary / Kerkwoordeboek (1970), wat gedeeltelik die werk van Karel Schoeman was nie. In watter mate ook woorde uit ander godsdienstale en sosiolekte - bv. Kaapse Moesliemafrikaans (vgl. Davids 1992) voorkom, is hier nie nagegaan nie.

\section{Voorbeeldmateriaal}

'n Kenmerk van die WAT was nog altyd die aanhalings (vgl. Toeligting p. xii, par. 2.9). Sover vasgestel kon word, kom daar geen poëme voor nie. Die voorbeeldmateriaal bestaan deurgaans uit sitate met bronvermelding (outeur en datum) en illustreer die semantiese, sintaktiese en pragmatiese funksie van 'n bepaalde leksikale item. Hier behoort egter die "bondigheidsbeginsel" (Lombard 1992: 153) toegepas te word. Die sitate is informatief as ' $n$ mens ' $n$ beeld van die Afrikaanse taalgebruik oor die afgelope honderd jaar wil kry, maar die oordadige en skynbaar willekeurige vermelding van sitate kan ook 'n irriterende effek hê op die woordeboekgebruiker. Oor die algemeen is die sitate goed gekies; die probleem lê in die hoeveelheid en in die rangskikking. Die leksikograwe van die WAT beskik oor so ' $n$ magdom van voorbeeldmateriaal dat die seleksie klaarblyklik problematies word.

Hoewel die Woordeboek nie op 'n historiese grondslag gebou is nie, kan 'n mens dikwels die ouderdom en die register van 'n woord aan die hand van die gebruikte aanhalings nagaan. Hier ontbreek egter 'n vaste redaksionele beleid: soms word die aanhalings histories gerangskik, heel sporadies word daar van vroeë, argivale bronne en gepubliseerde Kaapse tekste gebruik gemaak (bv. kuier uit 1766, kwas (1) uit 1850, kropslaai - by Van Riebeeck, kros vir karos - by Tregardt 1838, Teenstra 1830, Mansvelt 1884), maar dit is sonder enige stelselmatigheid. Soms is daar lang reekse van sitate sonder dat hulle semantiese, regionale of registerverskille illustreer. Van kroonkandelaar word daar bv. 7 aanhalings van dieselfde tipe en betekenis verskaf. Dit maak die Woordeboek wel informatief en onderhoudend om te lees, maar dit affekteer die struktuur en die funksie van die woordeboek. By lang artikels soos krag (34 kolomme), kruis (16 kolomme), kritiek (15 kolomme), kroon (13 kolomme), kos ( 9 kolomme), kraak ( 9 kolomme), kring ( 8 kolomme), kultuur (7 kolomme), krisis ( 5 kolomme), om maar 'n paar te noem, word m.i. gans te veel aanhalings gegee. Hier sou 'n drastiese besnoeiing die effektiwiteit van die Woordeboek beslis verhoog. Soos Lombard (1992: 148-164) beklemtoon, moet die "bondigheidsbeginsel" nie net ten opsigte van definiense toegepas 
word nie, maar ook by die keuse van sitate. Ook in 'n verklarende woordeboek soos die WAT behoort daar na kort en informatiewe voorbeeldmateriaal gestreef te word (Mostert 1988: 156).

\section{Spreekwoorde en gesegdes}

Dit sou 'n studie op sy eie verg om al die gesegdes, spreekwoorde en ander idiomatiese uitdrukkings te beskryf wat hier so volledig vermeld word. By die deurlees van WAT VIII word 'n mens opnuut getref deur die sterk idiomatiese inslag van Afrikaans, die rykdom aan spreekwoorde en die lekker, aardse sêgoed. Die woordeboekgebruiker is beslis dankbaar vir hierdie taamlik volledige vermelding van idiome. Soos in die Toeligting op p. xii vermeld, word 'n uitdrukking gewoonlik onder die "eerste vaste komponent" opgeneem en verklaar; dié kan egter die eerste selfstandige naamwoord of byvoeglike naamwoord of werkwoord of bywoord of voorsetsel of ander woordsoort wees! Al word die verwysingsmetode pertinent uitgespel, moet die gebruiker eers die redaksionele sisteem goed bestudeer; anders raak hy/sy totaal verward of gefrustreerd. Hoewel daar bv. meer as 100 gesegdes by die werkwoord kry voorkom, word hulle onder kry slegs vermeld, maar onder die soekwoord dan verklaar, bv. "'n bloutjie kry", "iets/iemand kan my kry", "'n blou skeen kry", "kry waarna jy soek". Daarmee word dubbele inligting verskaf, een oor die uitdrukking self, die ander oor die rol van bepaalde werkwoorde. Kry is klaarblyklik besonder frekwent; dikwels het dit in soortgelyke Nederlandse gesegdes 'n ander werkwoord vervang. Vanuit 'n historiese oogpunt is daar dus 'n massa indirekte maar hoogs relevante gegewens ten opsigte van die verskille tussen Afrikaans en Nederlands, en die funksionele lading van die werkwoord kry.

Ook by die uitdrukkings word daar heelwat sitate aangehaal, soms op historiese grondslag, maar in die meeste gevalle is dit suiwer toevallig as 'n ou bron vermeld word. In die artikel kwas kom 'n mens toevallig op die vroegste opgetekende voorbeelde van die gesegdes "iets aan jou kwas hê" (1850), "met dieselfde kwas geteer wees" (1861) af. Dit is uiters waardevolle inligting, jammer dat dit so versteek is in 'n massa ander gegewens. Sou dit nie moontlik wees om hier 'n historiese/chronologiese rangskikking te verskaf nie? In ander artikels soek 'n mens egter verniet na die vroegste gevalle van sekere uitdrukkings. Onder die lemma kous byvoorbeeld word die vroegste gevalle van die uitdrukkings "met die kous op die kop" (1863), "met die kous op sy klapperdop" (1863) en "(kouse) oor hulle koppe laat trek" (1868) .(vgl. Raidt 1992: 252-253) nie vermeld nie. Slegs een van die drie gesegdes word uit 'n bron van 1876 aangehaal. Hierdie onsistematiese dataversameling en bronneverwerking maak die WAT onbetroubaar vir historiese gebruik. 


\section{Etimologieё}

Een van die tekortkominge van die WAT is die feit dat die redaksie doelbewus wegskram van die aangee van etimologieë (vgl. Toeligting p. xi). Etimologiese verwysings word slegs "oorweeg" o.a. by "leenwoorde, leenvertalings, en basterwoorde uit nie-Afrikaanse tale", verder by wetenskaplike terme en 'n paar ander kategorieë. Dit kom weer eens neer op nog 'n lukraak keuse, hierdie keer t.o.v. die etimologie van woorde. Hoekom word die herkoms verklaar van woorde soos "kraal (via Oos-Ind. Ndl. <Port. curral)", "krabbetjie, kraw[w]eltjie, krawwe[r]tjie (<Mal. k(e)raboe, waarsk. <Port. cravo-)", lg. selfs met 'n argivale verwysing: "In 'n argiefstuk van 1709-1724 ...", verder "krediettranche (<Fr. tranche)", "krok (<Eng. crock)", "kroep (via Ndl. <Fr. croup)", "krupsie (<dial. Ndl. vir corruptie)", "kwad (<E. quad)", "kwêlafluit (<X, Z khwela)", en selfs Adam Tas se onnosele krankebedroewer "(hist.) Verafr. v/d skertsend-satiriese benaming vir 'n sieketrooster deur Adam Tas in sy dagboek gebruik ...", terwyl talle ander belangrike etimologieë (bv. kurang, kwansuis, kwas=lemoensap) met opset onverklaar bly? Hier word 'n mens pynlik bewus van die hibridiese opset van die WAT as 'n verklarende woordeboek wat slegs nou en dan etimologies, en slegs nou en dan histories te werk gaan. Dit weerspieël natuurlik ook die leemtes wat in die leksikografie van Afrikaans bestaan: ons besit.nog geen historiese woordeboek van Afrikaans nie, en die etimologieë van woorde is maar net gedeeltelik beskryf. Maar daar is beslis reeds baie navorsing gedoen en talle etimologieë is goed nagevors; bestaande studies soos die van Boshoff en Nienaber (1967), Scholtz $(1965,1972,1980,1985)$ e.a. behoort deeglik benut te word.

In hierdie verband lewer die nuwe Dictionary of South African English on Historical Principles (DSAE) wat nog onder bewerking is, die bewys dat etimologiese verwysings in ' $n$ hoë mate moontlik is en verskaf kan word. Die beknopte formule wat deur die DSAE-redaksie gebruik word (vgl. Dictionary of South African English ... Project description 1991), kan ook vir die WAT aanbeveel word. Skakeling met die DSAE-kantoor in Grahamstad sou seker vrugbaar kon wees.

\section{Ten slotte}

Die Woordeboek van die Afrikaanse Taal is nog nie eens halfpad deur die alfabet nie, daarom is dit seker nie te laat en ook nie onvanpas om nou nog aanbevelings vir die volgende dele van die WAT te maak nie, veral aangesien daar tog op die oomblik 'n fase van redaksionele besinning en heroriëntering aan die gang skyn te wees. Die WAT beteken vir Afrikaans wat die Woordenboek der Nederlandsche Taal vir Nederlands en die Oxford English Dictionary vir Engels en alle betrokke taalgebruikers van daardie tale beteken. As die WAT eers klaar is, sal dit die mees omvattende beskrywing van die Afrikaanse leksikon in die 
ruimste sin van die woord wees. Juis daarom sou 'n mens graag 'n stelselmatige uitbreiding wou sien van die historiese en etimologiese dimensies van woordbeskrywing, verder 'n ruimer gebruikmaking van regionale variante van Afrikaanse woorde om ook aan die verskillende variëteite van die Afrikaanse taal reg te laat geskied. Die Woordeboek van die Afrikaanse Taal wat by uitstek "gebruikervriendelik" is, sou beslis daarby baat.

\section{Aantekening}

- Hauptfleisch, D.C. (Hoofred.). 1991. Woordeboek van die Afrikaanse Taal, Agtste deel, KOS-KYW-. xxii +584 bladsye, 1 plaat en 1 volbladafteelding.

Die Buro van die WAT, Privaatsak X5018, Universiteit van Stellenbosch, 7600 Stellenbosch. Prys: leerband R142.50, plastiekband R71 (posgeld ingesluit).

\section{Verwysings}

Afrikaanse woordelys en spelreëls. 1991. Agste, verbeterde uitgawe. Kaapstad: Tafelberg.

Boshoff, S.P.E. en G.S. Nien aber. 1967. Afrikaanse etimologië̈. Die Suid-Afrikaanse Akademie vir Wetenskap en Kuns.

Church Dictionary / Kerkwoordeboek. 1970. Onder redaksie van die Taalkomitee B.S.A.K.B. Pretoria: K.A.S. (Katolieke Afrikanersentrum).

Combrink, J. 1979. Die sesde deel van die W.A.T. Standpunte 140, 32(2): 49-64

Davids, Achmat. 1992. Some Lexical Aspects of Cape Muslim Afrikaans. Lexikos 2: 39-62.

Dictionary of South African English on Historical Principles, Project Description. 1991. Rhodes University, Grahamstown.

Du Plessis, H. 1985. Suidwesafrikaans. Suid-Afrikanse Tydskrif vir Taalkunde. Geleentheidsuitgawe.

Gomes, D.J. 1962. 'n Ondersoek na die wenslikheid en noodsaaklikheid van 'n Katolieke woordeskat in Afrikaans. Ongepubliseerde Ph.D.-proefskrif. Universiteit van die Witwatersrand, Johannesburg.

Gouws, R.H. 1989. Leksikografie. Pretoria / Kaapstad: Academica.

Gouws, R.H. en F.A. Ponelis. 1992. Issues in the Development of Afrikaans Lexicography. SuidAfrikaanse Tydskrif vir Taalkunde. Supplement 12, April 1992.

Links, Tony. 1989. So Praat ons Namakwalanders. Kaapstad: Tafelberg.

Lombard, F.J. 1992. Voorbeeldmateriaal in woordeboeke. Lexikos 2: 148-164.

Mostert, N. 1988. Die funksie van poëme en sitate in die verklarende leksikografie. Tydskrif vir Geesleswetenskappe 28(2): 150-160.

Odendal, F.F. 1979. Plus positief en plus negatief: gedagtes na aanleiding van WAT VI (KLA-KLO). Tydskrif vir Geesteswetenskappe 19(1): 24-41.

Raidt, E.H. 1992. Taalvariasie in negentiende-eeuse Afrikaans. Tydskrif vir Geesteswetenskappe 32(4): 240-256.

Scholtz, J. du P. 1965. Afrikaans uit die vroeë tyd. Kaapstad: Nasou. 
Scholtz, J. du P. 1972. Afrikants-Hollands in die agtiende eeu. Kaapstad: Nasou. Scholtz, J. du P. 1980. Wording en ontwikkeling van Afrikans. Kaapstad: Tafelberg.

Scholtz, J. du P. 1985. Afrikaanse woorde en uitdrukkinge - eiegoed of erfgoed? Tydskrif vir Geesteswetenskappe 25(4): 235-290.

Van der Merwe, H.J.J.M. en F.A. Ponelis. 1991. Die korrekte woord. Pretoria: J.L. van Schaik.

Van der Waal-Braaksma, G. en O.J.O. Ferreira. 1986. Die Noordweste. Johannesburg: Genootskap vir Afrikaanse Volkskunde. 